\title{
Which One Is More Effective for Lower Urinary Tract Dysfunctions in Children? Pelvic Floor Contraction or Pelvic Floor Relaxation in Biofeedback Therapy
}

\section{Alt Üriner Sistem Disfonksiyonlu Çocuklarda Hangisi Daha Etkili Bir Tedavi Yöntemidir? Biofeedback Tedavisinde Pelvik Taban Kasılması veya Pelvik Taban Gevşemesi}

\author{
(D) Burak Köprü1, (D) Turgay Ebiloğlu2, (D) Giray Ergin1, (D) Engin Kaya2, (D) Yusuf Kibar1 \\ ${ }^{1}$ Koru Ankara Hospital, Clinic of Urology, Ankara, Turkiye \\ 2Gülhane Training and Research Hospital, Clinic of Urology, Ankara, Turkiye
}

What's known on the subject? and What does the study add?

Biofeedback treatment in children with lower urinary tract dysfunction will be a more effective treatment modality as it determines the biofeedback nature in accordance with the presence of electromyography activity.

\begin{abstract}
Objective: The objective of this study is to investigate the results of contraction- and relaxation-based biofeedback (BF) in children with lower urinary tract dysfunction (LUTD).

Materials and Methods: Between 2007 and 2017, we randomly directed children with the diagnosis of LUTD and refractory to standard urotherapy modifications via BF by using two different animations: animation $A$ with relaxation nature BF (RBF) and animation $B$ with contraction nature BF (CBF). The categories of non-response, partial response, and full response were defined as a 0-49\% decrease, 50-99\% decrease, and 100\% decrease in the LUTD Symptom score, respectively. Results of biofeedback using RBF or CBF were compared.

Results: There were 100 and 70 children in the RBF and CBF groups, respectively. Patients with an abnormal voiding pattern (abnormalVP) and a positive electromyography (EMG) activity (positive EMG) had a better resolution with RBF ( $p=0.001)$, whereas patients with abnormalVP and a negative EMG activity (negative EMG) had a better resolution with CBF ( $p=0.039)$. Despite being statistically insignificant, patients with a normal voiding pattern (normalVP) and positive EMG had a better resolution with CBF ( $p=0.452)$, whereas patients with normalVP and negative EMG had a better resolution with $\operatorname{RBF}(p=0.083)$.

Conclusion: The EMG activity identifies the BF nature in children with LUTD and abnormalVP. Importantly, positive EMG had better results with RBF, whereas negative EMG had better results with CBF.
\end{abstract}

Keywords: LUTD, Biofeedback, EMG activity, Voiding pattern, Contraction, Relaxation

Öz

Amaç: Alt üriner sistem disfonksiyonu (AÜSS) olan çocuklarda kasılma ve gevşeme bazlı biofeedback (BF) sonuçlarının araştırılması amaçlandı.

Gereç ve Yöntem: 2007-2017 yılları arasında AÜSS tanısı alan ve standart üroterapi tedavisine dirençli olan çocuklar iki farklı animasyon kullanılarak rastgele BF'ye yönlendirildi: Animasyon A gevşeme niteliğinde BF (RBF) ve animasyon B kontraksiyon niteliğinde BF (CBF) idi. Cevap vermeme, kısmi cevap ve tam cevap, AÜSS'de sırasıyla \%0 ila \%49 düşüş, \%50 ila \%99 düşüş ve \%100 düşüş olarak tanımlandı. RBF veya CBF kullanan biofeedback sonuçları karşılaştırıldı.

Bulgular: RBF ve CBF grubunda sırasıyla 100 ve 70 çocuk vardı. Hastalarda anormal işeme akımı (abnormalVP) ve pozitif EMG aktivitesi (positive EMG) olan hastalarda RBF ile daha anlamlı iyileşme $(p=0,001)$; anormalVP ve negatif EMG aktivitesi (negative EMG) olan hastalar $C B F$ ile daha anlamlı iyileşmeye sahip olduğu tespit edildi $(p=0,039)$; İstatistiksel olarak önemsiz olmasına rağmen, normal işeme akımı (normalVP) ve positive

Correspondence: Burak Köprü MD, Koru Ankara Hospital, Clinic of Urology, Ankara, Turkiye

E-mail: dr_burak83@yahoo.com ORCID-ID: orcid.org/0000-0003-0364-7347

Received: 04.10.2019 Accepted: 13.02 .2020

Cite this article as: Köprü B, Ebiloğlu T, Ergin G, Kaya E, Kibar Y. Which One Is More Effective for Lower Urinary Tract Dysfunctions in Children? Pelvic Floor Contraction or Pelvic Floor Relaxation in Biofeedback Therapy. Urol Surg 2020;7(3):211-217.

๑Copyright 2020 by the Association of Urological Surgery / Journal of Urological Surgery published by Galenos Publishing House. 
EMG olan hastalar CBF ile daha iyi çözünürlüğe sahip iken $(p=0,452)$; normalVP ve negative EMG hastalarında RBF ile daha anlamlı iyileşme gözlendi $(p=0,083)$.

Sonuç: LUTD ve Anormal VP'li çocuklarda, EMG aktivitesi biofeedback tedavisinin tipini belirlemektedir: positive EMG, RBF ile daha iyi sonuçlara sahip iken, negative EMG, CBF ile daha iyi sonuçlara sahiptir.

Anahtar Kelimeler: LUTD, Biofeedback, EMG aktivitesi, İşeme akımı, Kasılma, Gevşeme

\section{Introduction}

Biofeedback (BF) is a non-invasive and non-pharmacologic treatment option for lower urinary tract dysfunction (LUTD) in children. In 1970s, the first data of BF results were presented in the urology literature $(1,2)$. The above-described BF method was urodynamic bladder BF therapy that was performed during bladder filling in urodynamic testing. The animated voiding BF therapy in pediatric voiding dysfunction was first reported in 1990 (3). It was easier than urodynamic bladder BF therapy because of the lack of the usage of any invasive catheterization. Since then, there has been a wide clinical usage of animated voiding BF therapy for LUTD in children. In animated voiding BF, video computerized systems obtain the data from the body and let the children see, learn, and control their pelvic muscles (PM).

BF encompasses more than just teaching the pelvic floor relaxing techniques (PFRT) and standard urotherapy (SU) modifications, which are defined by conveying simpler explanations to children and parents about urinary tract functions, abnormal voiding, voiding posture, adapted standardized fluid intake, timed voiding, and proper diet. Some different studies have inferred the superiority of BF to PFRT and SU. For example, McKenna et al. (3) reported recovery rates of $89 \%$ and $90 \%$ in the symptoms of incontinence and enuresis, respectively. However, Vesna et al. (4) reported resolution rates of $83 \%$ and $66 \%$ in the SU + PFRT group, as well as resolution rates of $11 \%$ and $33 \%$ in only the SU group, respectively $(3,4)$. Additionally, Kibar et al. (5) documented better post-void residual (PVR) urine resolution in the BF group than in the SU group. However, there is still a need for more randomized controlled studies that aim to compare SU, PFRT, and BF (6).

There is no standardized BF method in the literature. Some centers only use curves as an animation and they have a relaxation-based nature (7); however, others use a wolf and a bird providing 3 seconds of submaximal contraction followed by 30 seconds of prolonged relaxation with a relaxation-based nature (8). Some others use dolphin that should pass over hoops with a contraction-based nature $(9,10)$. We believe that there may be differences among techniques, especially according to the relaxation or contraction nature.

In this study, we hypothesized that contraction-based and relaxation-based animated voiding BF techniques reveal different results in children with LUTD, and we have investigated the uroflowmetry (UF) results and electromyography (EMG) data.

\section{Materials and Methods}

The local ethics committee (Gülhane Training and Research Hospital Ethical Committee, protocol no: 26.11.2014/201407) approved this study's design, conduct, and procedures. We followed the Institution's Review Board of Human Subject Guidelines while performing this study. Informed consent was obtained from the participants' parents before conducting this study.

This study had been planned in a randomized nature, but we could not completely manage the randomization protocol due to children's claims regarding animations. Children mostly liked one animation more than the other. However, we managed to understand the prospective nature of study.

This is a retrospective study that includes the children with the diagnosis of LUTD and refractory to SU modifications without any history of urinary infection. These children were followed up at our institute between 2007 and $2017(4,11)$. The data from all the children who applied to the urology clinic and underwent $\mathrm{BF}$ with the assistance of a urology nurse by using two different animations reported no differences: relaxation nature biofeedback (RBF) with 5 seconds of contraction followed by prolonged 20 seconds of relaxation by using the animation of a mushroom and a bird; and contraction nature biofeedback (CBF) with 15 seconds of contraction followed by 10 seconds of relaxation by using the animation of a submarine and a starfish.

We used the data of the children aged between 5 and 15 years without any medical treatment for LUTD in this study. Importantly, we obtained the medical data including the diet, the voiding habit, the defecation habit, the psychosocial problems, and the constitutional urologic abnormalities from all the children (12-14). In our clinic as a routine clinical practice, all the patients underwent a complete physical examination including a neurourologic examination focusing on the anal tone and voluntary control of the anal sphincter, the bulbocavernosus reflex, lower limb reflexes, and perineal sensitivity. We also recorded urinalysis, urine culture, serum urea and creatinine, the lumbosacral spine radiography, and the urinary ultrasonography of the patients. Additionally, we documented the answers of the 
normal defecation habits, physical examination, laboratory and radiological tests, and any psychosocial problems, which have been enquired from the parents. We also recorded the data of the three-day bladder diary for cataloging the voiding habit at their home under regular conditions. Among the answers, more than seven voids were defined as frequency (15). We used the LUTD Symptom score (LUTDSS) to compare the LUTD symptoms according to the different animations (16).

In our clinic, UF combined with perineal EMG that documents the pelvic floor contractions were performed for the determination of voiding phase deficit by our trained nurse with the urodynamic device (MMS 5000, by Colosseum, Netherlands) at our urodynamic laboratory. The individuals were instructed to come to the visit with an empty bladder. Before UF-EMG, they were informed to drink water to acquire the sufficient volume by bladder ultrasonography. The UF-EMG was performed at least two times; it was reviewed and determined under the decision of two different urologists. The UF-EMG curves were classified as normal, staccato-, tower-, and plateau-shaped (15). PVR was measured ultrasonographically by BladderScan BVI 6100 (diagnostic ultrasound, Bothell, WA) immediately after voiding. PVR of less than 21\% of estimated bladder capacity was defined as increased PVR (15).

The RBF and CBF were discussed with each parent, and there was no reported difference between these animations. The same trained nurse who performed UF-EMG also performed the BF therapies with the same MMS 5000 (Colosseum, the Netherlands) device. Two electrodes to show the external sphincter activity were placed at 3 and 9 o'clock positions in the perineal area. Another electrode was placed over the left thigh or rectus abdominis to identify the proper relaxation of these muscles. Children were asked to sit on the BF closet, which was specially designed for children with their feet on a basement, thus providing a relaxed position. The total treatment period was 6 months for each child. The children had a BF session at weekly intervals in the first month. Each session consisted of 20 minutes with RBF or CBF. After each BF session, children were told to continue to exercise their external sphincters with daily 30 contraction and relaxation cycles at their home by imagining the animation in their minds together with SU instructions. The children were controlled at the third month, and UF-EMG tests and control BF sessions were performed. Then, the children were told to continue to exercise their external sphincters. The final UF-EMG tests and BF sessions were then performed, and LUTDSS were analyzed at the sixth month. The categories of nonresponse, partial response, and full response were defined as a $0-49 \%$ decrease, $50-99 \%$ decrease, and $100 \%$ decrease in LUTDSS, respectively (12). Thereafter, we compared the results of BF by using both RBF and CBF.

\section{Statistical Analysis}

We performed statistical analysis by using Statistical Package for Social Sciences 20.0 software (SPSS 20.0 for MAC). We noted descriptive statistics with median (min-max), frequency, and percentiles. We used the Shapiro-Wilk, kurtosis, and skewness tests to assess the normalization of variables. Additionally, we used McNemar test to compare the nominal samples of LUTD symptoms before and after the BF therapies. We employed the related samples Wilcoxon Test to compare the scale samples of LUTD symptoms before and after the BF therapies. We used the chi-square test to compare the success rates of RBF and CBF groups. We also compared non-response and other types of responses. Probability of $p<0.05$ was accepted as statistically significant for this study.

\section{Results}

There were 120 and 92 children in the RBF and CBF groups, respectively. The data of the 20 patients in the RBF group and 22 patients in the CBF group were excluded from the study because we were unable to obtain the follow-up records. The RBF group comprised 100 children with 75 (75\%) girls and 25 (25\%) boys, and the CBF group comprised 70 children with 56 $(80 \%)$ girls and 14 boys $(20 \%)(p=0.78)$. The median ages in the RBF and CBF groups were 8.54 (min-max, 6-15) and 8.55 (minmax, 5-15) years, respectively $(p=0.721)$. Figure 1 depicts the symptoms of RBF and CBF groups ( $p=0.819)$. The median LUTDSS was 16.46 (min-max: 9-33) and 13.27 (min-max: 9-35) in the RBF and CBF groups, respectively.

In the RBF group, 49 patients had a staccato voiding pattern (StaccatoVP) with positive EMG activity (positive EMG), 20 had StaccatoVP with a negative EMG activity (negative EMG), 17 had a normal voiding pattern (normalVP) with positive EMG, 5 had normalVP with negative EMG, 6 had a tower voiding pattern (TowerVP) with positive EMG, and 3 had a plateaushaped voiding pattern (plateauVP) with positive EMG. With BF therapy, the complaints of daytime incontinence $(p=0.001$; success $=0.43)$, enuresis $(p=0.001$; success $=0.51)$, dysuria ( $p=0.027$; success $=0.52)$, incomplete emptying $(p=0.035$; success $=0.68)$, urgency ( $p=0.001$; success $=0.47)$, making holding maneuvers ( $p=0.001$; success $=0.49)$, urgency incontinence $(p=0.001 ;$ success $=0.56)$, and frequency $(p=0.045$; success $=0.53)$ demonstrated a statistically significant change as compared to baseline. However, strain $(p=0.263$; success $=0.31)$ and intermittency $(p=0.54$; success $=0.38)$ showed no statistically significant changes. The median LUTDSS decreased from 16.46 (min-max: 9-33) to 7.38 (min-max: 1-22) ( $p=0.001)$. In total, 35 $(35 \%)$ patients had increased PVR, and the median PVR of these patients was 92 (min-max: 22-197) mL. After BF, 19 patients with increased PVR showed resolution (PVR of less than 21\% 


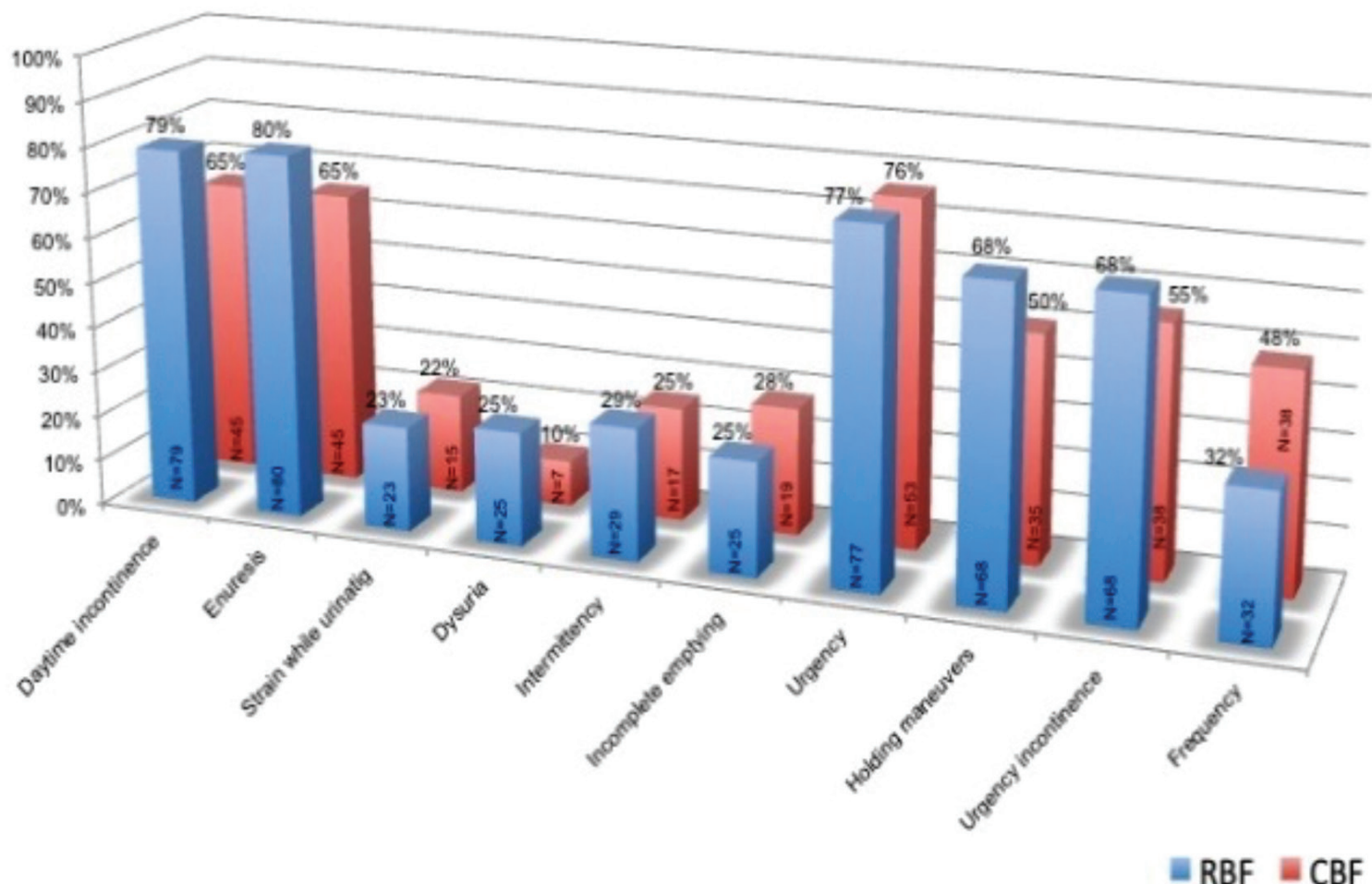

Figure 1. Symptoms of patients according to animations

of estimated bladder capacity). PVR decreased to 51 (min-max: $23-92)$ in rest of the 16 patients $(p=0.451)$.

In the CBF group, 16 patients had StaccatoVP with positive EMG, 16 had StaccatoVP with negative EMG, 19 had normalVP with positive EMG, 10 had normalVP with negative EMG, 4 had TowerVP with positive EMG, 1 had TowerVP with negative EMG, and 4 had plateauVP with positive EMG. After BF therapy, the complaints of daytime incontinence $(p=0.004$; success $=0.54)$, enuresis $(p=0.009 ;$ success $=0.52)$, urgency $(p=0.001$; success $=0.49)$, making holding maneuvers $(p=0.02$; success $=0.51)$, urgency incontinence $(p=0.004$; success $=0.55)$, and frequency $(p=0.041$; success $=0.57)$ had a statistically significant change. However, strain $(p=0.542$; success=0.1), dysuria $(p=1$; success $=0)$, intermittency $(p=0.109$; success $=0.38)$, and incomplete emptying $(p=0.345$; success $=0.35)$ did not show any significant changes. The median LUTDSS decreased to 9.13 (min-max: 1-27) ( $p=0.001)$. In total, 28 (40\%) patients had increased PVR, and the mean PVR of these patients was 67.43 (min-max: 25-142) mL. After BF, 18 patients with increased PVR showed resolution (PVR of less than 21\% of estimated bladder capacity). PVR decreased to 42 (min-max: 21-82) in rest of the 10 patients $(p=0.362)$.

Table 1 shows the success of BF in accordance with the UFEMG patterns and symptoms. The statistically significant points in this table are as follows: patients with abnormal VP (abnormalVP) and positive EMG had a better resolution with $\operatorname{RBF}(p=0.001)$, whereas patients with AbnormalVP and negative
EMG had a better resolution with CBF ( $p=0.039$ ). Despite being statistically insignificant, patients with normalVP and positive EMG had a better resolution with $\operatorname{CBF}(p=0.452)$, and patients with NormalVP and negative EMG had a better resolution with $\operatorname{RBF}(p=0.083)$.

\section{Discussion}

Abnormally learned behaviors of voiding cause a spectrum of symptoms such as daytime incontinence, enuresis, urgency, urgency incontinence; this condition is termed as LUTD (15) There are two main subgroups of LUTD: overactive bladder $(O A B)$ and dysfunctional voiding (DV) (12). BF is used as a noninvasive and non-pharmacological treatment option for both the subgroups of LUTD. Glazier et al. (17) reported symptom improvement at the rate of $85.7 \%$ in 89 patients by $\mathrm{OAB}$. Yamanishi et al. (18) also reported a cure rate of $65.7 \%$ and improvement rate of $11.4 \%$ in 35 patients. Meijer et al. (19) documented success and improvement rates of $42.9 \%$ and $31.4 \%$, respectively, in refractory cases. Success rates of daytime incontinence, nocturnal enuresis, constipation, and encopresis were defined at 89\%, 90\%, and 100\%, respectively, for DV (3). Prona et al. reported that the success rates of BF on enuresis, as a component of DV, were $87.1 \%$ and $80 \%$ in the second and fourth years, respectively (20). Hence, BF is used for all the subgroups of LUTD when PFRT and SU were failed, and also before initiating the medical therapy. 
Table 1. Success of biofeedback by using relaxation biofeedback (animation A) and contraction biofeedback (animation B) according to the electromyography activity in the uroflowmetry pattern.

\begin{tabular}{|c|c|c|c|c|c|c|c|}
\hline \multirow[b]{2}{*}{ Voiding pattern } & \multirow{2}{*}{\multicolumn{2}{|c|}{ Electromyography activity Response }} & \multicolumn{2}{|c|}{ Animation A } & \multicolumn{2}{|c|}{ Animation B } & \multirow{3}{*}{$\begin{array}{l}p \\
0.083\end{array}$} \\
\hline & & & Frequency & Percent (\%) & Frequency & Percent (\%) & \\
\hline \multirow{3}{*}{ Normal } & Negative & None & 3 & 60.0 & 8 & 80.0 & \\
\hline & \multirow[b]{2}{*}{ Positive } & None & 9 & 52.9 & 8 & 42.1 & 0.452 \\
\hline & & Partial & 8 & 47.1 & 4 & 21.1 & \\
\hline \multirow{2}{*}{ Tower } & \multirow{2}{*}{ Positive } & None & 2 & 33.3 & 2 & 50.0 & 0.037 \\
\hline & & Partial & 4 & 66.6 & 2 & 50.0 & \\
\hline \multirow{3}{*}{ Staccato } & \multirow[b]{2}{*}{ Negative } & None & 12 & 60.0 & 4 & 25.0 & 0.04 \\
\hline & & Partial & - & - & 4 & 25.0 & \\
\hline & Positive & Full & 11 & 22.4 & 2 & 12.5 & \\
\hline Plateau & Positive & None & - & - & 2 & 50.0 & 0.034 \\
\hline \multirow{2}{*}{\multicolumn{2}{|c|}{ Full }} & Partial & - & - & 2 & 50.0 & \\
\hline & & 3 & 100.0 & - & - & & \\
\hline
\end{tabular}

LUTD is related to two organs: bladder and PM. In a UF-EMG chart, EMG reflects the PM function, and flow pattern along with EMG activity that reflects the combination of both activities of bladder and PM. NormalVP in UF has a bell-shaped regular pattern, StaccatoVP has sharp peaks and troughs in the flow curve, TowerVP has a high amplitude curve with short duration, and PlateauVP pattern has a low amplitude with a longer duration. EMG activity might be accompanied with these flow patterns (15). StaccatoVP and NormalVP with positive EMG were the most detected UF-EMG patterns in our study, thus expressing deficits in both bladder and PM.

Urodynamic bladder BF therapy has been believed as an alternative method for the treatment of LUTD by illustrating both bladder and PM movements since 1970s. The technique resembles urodynamic testing: PM contraction was continued during bladder filling, till to the willingness to voiding. At the end of the filling, when the child felt the voiding sensation, voiding was accomplished with suitable PM relaxation. This was repeated several times when the catheters were inside the body. In 1978, Cardozo et al. (1) reported six patients with LUTD and demonstrated significant success. In 1979, Maizels et al. (2) reported the cases of three patients undergoing urodynamic bladder BF and showed success in two patients. In 1982, Sugar and Firlit (21) reported ten patients undergoing urodynamic bladder BF with success in eight of them. However, the main limitation of the urodynamic bladder BF was invasiveness.
McKenna et al. (3) has reported the first animated voiding BF results in 1999. The technique has gained popularity as a noninvasive method with good resolution rates in the symptoms of LUTD. Since then, several reports have been published regarding the animated voiding BF data in children with LUTD. However, each technique has different standardization procedure with the focus on different aspects of PM. In Glazier et al.'s (17) report, children were instructed to perform five quick contractions during a 5-second period, which was followed by a 5-second relaxation period. The children performed these exercises for 10 minutes or until the exercises were mastered. After each BF session, the children were asked to do the exercise at least three times per day at home. At the fourth month, they reported $86 \%$ resolution in frequency (17). This technique was predominantly focused on PM relaxation. We have previously reported that the children underwent BF by using an animation of a wolf and a bird providing 3 seconds of submaximal contraction followed by 30 seconds of prolonged relaxation (22) with the success rates of $64 \%, 59 \%, 50 \%$, and $66 \%$ in enuresis, daytime incontinence, urgency, and urgency incontinence, respectively. We mainly focused on the relaxation in our method. In another study, children underwent BF by using different animations (dolphin, bird, monkey, etc.), and they had to tighten their PM according to the instructions provided by computer games. The total BF time was 6 months, and they have reported success rates of $75-84 \%$ and $68 \%$ in the symptoms of frequency and urgency, respectively (10). The key part of this method was contraction. In Kaye and Palmer (9) reports, BF was conducted by using a 
dolphin and a water band. The children had to contract PM to maintain the swimming of dolphin in the water band. There were success rates of $84 \%, 92 \%, 89 \%$, and $90 \%$ in enuresis, daytime incontinence, urgency, and frequency symptoms, respectively (9). This technique was mainly focused on contraction.

McKenna (6) provided the following conclusion for our previous study: "our future investigations should be directed toward understanding how the pelvic floor causes changes in bladder function, and we need to standardize and simplify BF treatment methods" (8). This conclusion led us to consider the possibility of improvement in the success of animated voiding BF in LUTD, and we assumed that the contraction or relaxation nature of the animated voiding BF might play a role in the success of BF, which was the aim of this study. Here both techniques have good resolution effects in the symptoms. However, patients with AbnormalVP and positive EMG had better resolution rates with RBF, whereas patients with AbnormalVP and negative EMG had better resolution rates with CBF. We concluded that the main pathology in patients with abnormalVP and positive EMG is the inappropriate contraction of PM during voiding; therefore, performing RBF yields better results by making the children learn how to relax the PM. For patients with abnormalVP and negative EMG, the main pathology is likely to appear at the bladder, and performing CBF reveals better results by compensating the abnormal movements of bladder.

\section{Study Limitations}

Our study has limitations. First, we had a small sample size. Second, we were unable to conduct analysis according to the symptoms. We could not completely manage the randomization protocol due to children's claims about animations. Children mostly liked one animation more than the other. There is an urgent need of future studies that are designed with respect to the comparisons of symptoms with UF-EMG patterns along with the aspects of contraction- and relaxation-based animated voiding BF.

\section{Conclusion}

The patients with LUTD and abnormaIVP EMG activity identify the BF type. Positive EMG had better results with RBF, whereas negative EMG had better results with CBF. There is an urgent need of future studies that are designed with respect to the comparisons of symptoms with UF-EMG patterns with the aspects of contraction- and relaxation-based animated voiding BF.

\section{Ethics}

Ethics Committee Approval: The local ethics committee (Gülhane Training and Research Hospital Ethical Committee) approved the design, protocol and procedures of the study (protocol no: 26.11.2014/2014-07).
Informed Consent: Informed consent form was filled out by all the parents of the participants.

Peer-review: Externally peer-reviewed.

\section{Authorship Contributions}

Concept and Design: B.K., T.E., Data Collection and/or Processing: B.K., G.E. Analysis and/or Interpretation: T.E., Literature Research: E.K., Writing: B.K., T.E., Y.K.

Conflict of Interest: No conflict of interest was declared by the authors.

Financial Disclosure: The authors declared that this study received no financial support.

\section{References}

1. Cardozo L, Stanton SL, Hafner J, Allan V. Biofeedback in the treatment of detrusor instability. Br J Urol 1978;50:250-254.

2. Maizels $M$, King LR, Firlit CF. Urodynamic biofeedback: a new approach to treat vesical sphincter dyssynergia. J Urol 1979;122:205-209.

3. McKenna PH, Herndon CD, Connery S, Ferrer FA. Pelvic floor muscle retraining for pediatric voiding dysfunction using interactive computer games. J Urol 1999;162:1056-1062.

4. Vesna ZD, Milica L, Stankovic I, Marina V, Andjelka S. The evaluation of combined standard urotherapy, abdominal and pelvic floor retraining in children with dysfunctional voiding. J Pediatr Urol 2011;7:336-341.

5. Kibar Y, Piskin M, Irkilata HC, Aydur E, Gok F, Dayanc M. Management of abnormal postvoid residual urine in children with dysfunctional voiding. Urology 2010;75:1472-1475.

6. McKenna PH. Current role of biofeedback for pediatric lower urinary tract symptoms. J Urol 2015;193:14-15.

7. Khen-Dunlop N, Van Egroo A, Bouteiller C, Biserte J, Besson R. Biofeedback therapy in the treatment of bladder overactivity, vesico-ureteral reflux and urinary tract infection. J Pediatr Urol 2006;2:424-429.

8. Yagci S, Kibar Y, Akay O, Kilic S, Erdemir F, Gok F, Dayanc M. The effect of biofeedback treatment on voiding and urodynamic parameters in children with voiding dysfunction. J Urol 2005;174:1994-1997; discussion 19971998.

9. Kaye JD, Palmer LS. Animated biofeedback yields more rapid results than nonanimated biofeedback in the treatment of dysfunctional voiding in girls. J Urol 2008;180:300-305.

10. Tugtepe H, Thomas DT, Ergun R, Abdullayev T, Kastarli C, Kaynak A, Dagli TE. Comparison of Biofeedback Therapy in Children With Treatment-refractory Dysfunctional Voiding and Overactive Bladder. Urology 2015;85:900-904.

11. De Paepe H, Renson C, Hoebeke P, Raes A, Van Laecke E, Vande Walle J. The role of pelvic-floor therapy in the treatment of lower urinary tract dysfunctions in children. Scand J Urol Nephrol 2002;36:260-267.

12. Austin PF, Bauer SB, Bower W, Chase J, Franco I, Hoebeke P, Rittig S, Vande Walle J, von Gontard A, Wright A, Yang SS, Nevéus T. The standardization of terminology of lower urinary tract function in children and adolescents: update report from the Standardization Committee of the International Children's Continence Society. J Urol 2014;191:1863-1865.e13.

13. Kibar Y, Ors O, Demir E, Kalman S, Sakallioglu O, Dayanc M. Results of biofeedback treatment on reflux resolution rates in children with dysfunctional voiding and vesicoureteral reflux. Urology 2007;70:563-566.

14. Van Hoecke E, Baeyens D, Vanden Bossche H, Hoebeke P, Vande Walle J. Early detection of psychological problems in a population of children with 
enuresis: construction and validation of the Short Screening Instrument for Psychological Problems in Enuresis. J Urol 2007;178:2611-2615.

15. Nevéus T, von Gontard A, Hoebeke $P$, Hjälmås K, Bauer S, Bower W, Jørgensen $\mathrm{TM}$, Rittig S, Walle JV, Yeung CK, Djurhuus JC. The standardization of terminology of lower urinary tract function in children and adolescents: report from the Standardisation Committee of the International Children's Continence Society. J Urol 2006;176:314-324.

16. Akbal C, Genc Y, Burgu B, Ozden E, Tekgul S. Dysfunctional voiding and incontinence scoring system: quantitative evaluation of incontinence symptoms in pediatric population. J Urol 2005;173:969-973.

17. Glazier DB, Ankem MK, Ferlise V, Gazi M, Barone JG. Utility of biofeedback for the daytime syndrome of urinary frequency and urgency of childhood. Urology 2001;57:791-793.

18. Yamanishi T, Yasuda $K$, Murayama N, Sakakibara R, Uchiyama $T$, Ito $\mathrm{H}$. Biofeedback training for detrusor overactivity in children. J Urol 2000;164:1686-1690.
19. Meijer EF, Nieuwhof-Leppink AJ, Dekker-Vasse E, de Joode-Smink GC, de Jong TP. Central inhibition of refractory overactive bladder complaints, results of an inpatient training program. J Pediatr Urol 2015;11:21.e1-5.

20. Porena M, Costantini E, Rociola W, Mearini E. Biofeedback successfully cures detrusor-sphincter dyssynergia in pediatric patients. J Urol 2000;163:19271931.

21. Sugar EC, Firlit CF. Urodynamic biofeedback: a new therapeutic approach for childhood incontinence/infection (vesical voluntary sphincter dyssynergia). J Urol 1982;128:1253-1258.

22. Ebiloglu T, Ergin G, Irkilata HC, Kibar Y. The biofeedback treatment for nonmonosymptomatic enuresis nocturna. Neurourol Urodyn 2016;35:58-61. 